Warm up

\title{
"The unfriendly games"
}

\section{P McCrory}

A S I write this warm up, the 2002 Winter Olympics are in full flight at Salt Lake City, Utah. The media response has been rapid and savage. Already dubbed "the Unfriendly Games", the overwhelming security at the venues and the infrastructure problems is making life extremely difficult by all accounts.

Is this the shape of things to come? The thin end of the wedge and all that Following the September 11 tragedy and the fear of terrorist retaliation the need for security paramount, however, there are apparently over 15000 security personnel in Salt Lake City, more than in Afghanistan! The repeated security checks and bizarre attention to detail are surprising. For example, newspaper reports ${ }^{1}$ describe journalists attempting to enter the moguls event at $7.00 \mathrm{am}$ and having a delay of over an hour in $-12^{\circ} \mathrm{C}$ temperatures at the security checkpoint. Similar delays occurred at the speed skating venue where overzealous officials apparently insisted on inspecting every single credit card and piece of paper in wallets and dismantling pens, presumably looking for very small bombs. Remember these measures are for people already vetted and security cleared and who carry picture and bar coded ID passes. Heaven help the public.

Not even the athletes are immune. Reports of Larissa Lazutina, the veteran Russian skier having her water bottle

\section{Drugs in sport}

\section{Do drug cheats ever prosper?}

\section{P McCrory}

\section{The systems designed to eradicate drug use and cheating in sport need to be improved}

R ecent observers of international sporting meetings may have been disheartened yet again by the ongoing battle against the use of banned drugs in sport. This is particularly so for sports medicine clinicians, who usually attend these athletic meetings voluntarily and may be inadvertently brought into these controversial matters.

Often a team doctor is asked to chaperone an athlete during a drug test or provide information to the testing authorities about recent prescribed medication. The media often fails to see a distinction in the roles of medical staff, and, if an athlete tests positive to a banned agent, then the team medical staff are often tarred with the same accusatory brush. As sports medicine clinicians, we follow the various rules and regulations that govern each sport from the drugs issue. If an agent is banned, then we should not administer it to an athlete. How then do we gain the understanding of the media in distinguishing the roles of the medical staff in this area?

Another problem that continues to crop up is when drug testing procedures are not followed, and an athlete has a "negative" test because of this breakdown in procedure. This was the situation recently at the International Association of Athletics Federations (IAAF) Athletic World Championships in Edmonton. Most sporting bodies have introduced anti-doping regulations which serve as a set of rules for testing and penalising athletes. In Edmonton, there was a breakdown in the drug testing procedure, which requires both urine and drug samples to be taken when examined by security caused some dismay. She was reported as saying "this is my fifth Olympic Games and I have never seen such a thing ... it is really a put down for the athletes."

It is a frightening prospect if heightened security becomes the norm at future sport events. It would seem there must be some sort of compromise possible. Being seen to have a security presence is one thing but when the presence interferes with athletes in their quest for Olympic gold then the whole spirit of the Olympic movement is called into question. One can only wonder if these games were held outside the US, would the same presence be required. The cost of the security measures for these Winter Games we are told is \$US 310 million. All we can say that if you want to see at an event, get there early and hope that the person you want to watch is not up early! Oh and bring a blanket-you may have to wait.

Br J Sports Med 2002;36:79

\section{REFERENCE}

1 Magnay J. Overzealous security makes getting to venues an Olympic event in itself. The Age (Melbourne) February 11, 2002 pS1.

testing for erythropoietin (EPO), resulting in a test being declared invalid.

Apart from the procedural difficulties, the off field arguments between athletes before the final were a blow to the credibility of the IAAF. Gabriella Szabo, the reigning World and Olympic Champion, made her criticism of the process very public, and, at one point, agonised about boycotting the race entirely. The English also threatened a boycott, and one athlete, Paula Radcliffe, held up a homemade sign during the semifinal saying: "EPO cheats out".

In this case, the system designed to eradicate drug use and cheating in sport was flawed. The IAAF was in an impossible situation. If they had banned an athlete from competing on the basis of an inadmissible test result, presumably the athlete would have successfully appealed to the courts to be reinstated. A frightening prospect for any sports administrator.

Br J Sports Med 2002;36:79

\section{Author's affiliations}

P McCrory, Centre for Sports Medicine Research and Education and the Brain research Institute, University of Melbourne, Melbourne, Australia

Correspondence to: Dr McCrory, PO Box 93 Shoreham, Victoria 3916, Australia:

pmccrory@compuserve.com 